\title{
Drug usage analysis and health care resources consumption in naïve patients with rheumatoid arthritis
}

\section{Diego Sangiorgi' \\ Maurizio Benucci ${ }^{2}$ \\ Carmela Nappi ${ }^{3}$ \\ Valentina Perrone' \\ Stefano Buda' \\ Luca Degli Esposti'}

'CliCon S.r.l., Health, Economics and Outcomes Research, Ravenna, ${ }^{2}$ Unit of Rheumatology, S. Giovanni di Dio Hospital, Florence, ${ }^{3}$ Bristol Myers

Squibb S.r.I., Rome, Italy
Correspondence: Luca Degli Esposti CliCon S.r.l., Health, Economics and Outcomes Research, Via Salara, 36, 48I 00 Ravenna, Italy

Tel +3954438393

Fax +39544212699

Email luca.degliesposti@clicon.it
This article was published in the following Dove Press journal:

Biologics: Targets and Therapy

6 November 2015

Number of times this article has been viewed

Objectives: The use of biologic agents has revolutionized the management of rheumatoid arthritis (RA) in the past 2 decades. These biologic agents directly target molecules and cells involved in the pathogenesis of RA. The purpose of this study was to assess the usage of biologic agents in terms of persistence to treatment, dose escalation, and consumption of health care resources (hospitalizations, drugs, and outpatients service) in the real clinical practice in naïve patients with RA.

Methods: We conducted a real-world, retrospective, observational cohort study based on data obtained from administrative databases of three Local Health Units in Italy. The population included adults diagnosed with RA who had at least one prescription between January 1, 2009 and December 31, 2011, for a biologic that was approved for treatment of RA. The patients were followed for 12 months after enrollment. The clinical characteristics of the patients enrolled in this study were also investigated in the 1 -year period before the index date. The main and secondary endpoints were evaluated only in biologic-naïve patients without switches. The overall health care costs for patients were evaluated.

Results: A total of 594 patients met the study criteria (mean age $53.5 \pm 13.5$, female:male ratio $=3: 1$ ). Thirty-nine percent received etanercept, $25 \%$ adalimumab, $14 \%$ infliximab, $10 \%$ abatacept, 9\% tocilizumab, and 3\% golimumab. After 1 year of observation, patients showed similar use of other RA-related medication. For the naïve patients without switches, the persistence levels were: $78 \%$ for etanercept, $72 \%$ for tocilizumab, $71 \%$ for adalimumab, $69 \%$ for infliximab, and $64 \%$ for abatacept. For all agents, dose escalation was $21.4 \%$ for infliximab, $11.5 \%$ for adalimumab, $5.6 \%$ for abatacept, $4 \%$ for tocilizumab, and $3.8 \%$ for etanercept. The annual costs per treated patients were $€ 12,803$ for adalimumab, $€ 11,924$ for etanercept, $€ 11,830$ for tocilizumab, $€ 11,201$ for infliximab, and $€ 10,943$ for abatacept.

Conclusion: The role of biologic therapies in the treatment of RA continues to evolve; our study reflects real-world drug utilization data in adult patients with RA. These observations could be used by decision makers to support formulary decisions, although further research is needed using a larger sample to validate these results.

Keywords: rheumatoid arthritis, biologic agents, real-world data

\section{Introduction}

Rheumatoid arthritis (RA) is a chronic, inflammatory autoimmune disease of unknown etiology affecting $\sim 1 \%$ of the world population. ${ }^{1,2}$ The health-related quality of life in patients with RA is significantly reduced by pain, fatigue, loss of bodily function for progressive destruction of joint tissue, and a heavy economic burden associated with disease progression. 
According to the European League Against Rheumatism recommendations, several treatment options are available for patients with RA; ${ }^{3}$ medications for RA include nonsteroidal anti-inflammatory drugs, corticosteroids, disease-modifying antirheumatic drugs (DMARDs), and biologic therapies.

The development of biologic agents during the last few decades has revolutionized the treatment of RA, improving outcomes for patient refractory or intolerant to conventional treatment and, in some cases, inducing clinical remission. ${ }^{4}$ Biologic agents are recommended for use in patients with active RA who have poor response or intolerance to traditional DMARDs. ${ }^{3}$ According to the last European recommendations, biologic agents can be administered for synthetic DMARDnaïve patients with unfavorable prognostic signs, including very active disease or early structural damage. ${ }^{3}$ The major targets of these biologic therapies include cytokines, immune cells, and some co-stimulatory molecules..$^{5}$ The biologics licensed for use in this indication are tumor necrosis factor- $\alpha$ antagonists (four given subcutaneously: adalimumab, certolizumab-pegol, etanercept, and golimumab; and infliximab, given as intravenous infusions), the interleukin-6-receptor antagonist tocilizumab, the anti-B-cell agent rituximab, as well as the T-cell co-stimulation modulator abatacept, and the interleukin-1 inhibitor, anakinra. ${ }^{3}$ All these biologic agents have been proven effective in alleviating the symptoms and in slowing structural disease progression in patients with RA and have comparable safety profiles. These agents differ in their routes of administration, dosage, and dose schedules; ${ }^{6-14}$ however, none of these biologics is clearly preferable to the others, since the efficacy and safety profiles were similar in several meta-analyses and a few head-to-head trials. ${ }^{15}$

Unfortunately, these agents are not universally effective. Previous studies have shown that some patients require an upward dose adjustment or shortened dose interval to achieve or maintain a clinical response; for patients who are not likely to benefit from intensified therapy, clinicians will often switch to another biologic class with a different mechanism of action. ${ }^{3,16-18}$

Observational studies have indeed reported comparable effectiveness between biologic drugs in clinical practice, but differences in utilization or in the total cost of care. ${ }^{19-24}$ Considering that the use of biologic agents is associated with significant costs, ${ }^{25}$ an important issue in the face of limited health care resources, to document the information of reallife practice could enhance the decision-making process in the management of RA patient.

The primary objective of the present study was to assess the drug usage in naïve patients with RA in terms of therapeutic strategy used, the route of administration of the therapeutic strategy (eg, intravenous or subcutaneous), persistence, dose escalation, and co-medication related to RA. The second objective was to estimate the total cost per patient with RA treated with biologics - drug treatment, diagnostic services, specialist visits, and hospital stays - in patients with RA.

\section{Methods \\ Data source}

The study was conducted using administrative databases of three Italian Local Health Units (LHU) in Campania (LHU Caserta), Lombardy (LHU Bergamo), and Lazio (LHU Roma D).

We used the Health-Assisted Subjects Database, containing patients' demographic data; Territorial Pharmacy Database, providing information for each medication prescription, such as the prescribing physician's number, the Anatomical Therapeutic Chemical code of the drug purchased, the number of packages, the number of units per package, the dosages, the unit cost per package, and the prescription date; Hospital Discharge Database, which includes all hospitalization data with the discharge diagnosis codes classified according to the International Classification of Diseases, Ninth Revision, Clinical Modification (ICD-9-CM); and the Ambulatory Care Specialist, which records outpatient specialist services (visits, laboratory tests, diagnostic tests) provided to the patient, such as the type of visit and the date of the visit. These administrative databases are complete, include validated data, and have been used in previous epidemiologic studies. The Italian Ministry of Health defined these archives as 100\% complete and $95 \%$ accurate. ${ }^{26}$ In compliance with privacy laws, the patients' identification code was encrypted and the individuals/bodies involved in processing of the data for the purposes of the analysis were blinded to the identification of patients. ${ }^{27}$ The patient code in each database permitted electronic linkage between all databases. In order to guarantee patient privacy, each subject was assigned an anonymous univocal numeric code. No identifiers related to patients were provided to the researchers. The LHU Ethics Committees approved the study.

\section{Cohort definition}

The study was a retrospective cohort study that included all patients ( $\geq 18$ years old) with a diagnosis of RA between January 1, 2009 and December 31, 2011 (enrollment period). The RA diagnosis was retrieved from hospitalization (ICD9-CM code 714) or specific exemption code. 
The date of the first prescription of biologic agents (ie, abatacept $\left[\right.$ Orencia $^{\circledR}$ ], adalimumab [Humira ${ }^{\circledR}$ ], etanercept $\left[\right.$ Enbrel $\left.^{\circledR}\right]$, golimumab $\left[\right.$ Simponi $\left.{ }^{\circledR}\right]$, infliximab $\left[\right.$ Remicade $\left.^{\circledR}\right]$, and tocilizumab [RoActemra]) in RA patients was defined as the "index date", which represents the enrollment date of the individual patient, who was then followed for 1 year ("follow-up"). Anakinra [Kineret $\left.{ }^{\circledR}\right]$ and certolizumab pegol $\left[\mathrm{Cimzia}^{\circledR}\right]$, as well as rituximab [Mabthera] were not included as index drugs in this analysis due to insufficient sample size. The clinical characteristics of the patients enrolled in this study were also investigated in the 1-year period before the index date. Naïve patients were defined as those who had no prior biologic agents prescription filled during the 1 year preceding the enrollment date.

The presence of previous use of DMARDs, antibiotics, or pain medications was also evaluated. Hospitalizations related to RA were identified by ICD-9-CM codes (primary or accessory discharge reasons). The level of disease severity was measured using the MedStat Disease Staging Software ${ }^{\circledR}$, which classifies the pathologies on the basis of their complications (stage 1, no complications; stage 2, local complications; stage 3, complications to multiple sites or systemic complications). Comorbidities were measured using the Charlson Comorbidity Index (CCI), ${ }^{28}$ the sum of weights related to each condition (ie, myocardial infarction, cancers, diabetes, ulcer) identified through treatments and hospitalizations. All comorbidities were evaluated in the 1-year period before the index data; the CCI score reflects a patient's overall health status. This methodology has been widely used as a way to compare disease severity in retrospective analyses when data are unavailable. ${ }^{23}$

According to the biologic therapeutic strategy used at the index date, naïve patients without switches were characterized according to usage of RA-related co-medication, persistence of treatments, dose escalation and outpatient visit, and RA-related hospitalization. Patients transferred to another LHU during the whole observation period (previous year and follow-up period) were excluded from analysis.

Patients were classified as persistent if they were still on treatment with the index drug during the last 3 months of observation. Dose escalation was evaluated as the change in the average dose prescribed between two following prescriptive intervals during the 12 months of observation. Dose escalation was defined as having two consecutive prescription with an average weekly dose $30 \%$ greater than the initial average weekly dose, according to previously published methods. ${ }^{29}$ To take into account the induction phase, dose escalation was identified following the third infusion; patients who had at least five infusions were included. ${ }^{30}$

\section{Cost analysis}

Cost of illness was evaluated in biologic-naïve patients without switches after the index biologic date. Drug costs were evaluated using the National Health Service purchase price. Hospitalization costs were determined using the DiagnosisRelated Group tariff; these costs were related to RA main, secondary, or other diagnosis of hospitalizations. Other inherent hospitalization considered for disease staging were uveitis, fusion of metacarpophalangeal interphalangeal joint spaces, carpal tunnel syndrome, anemia, Felty's syndrome, pneumoconiosis, interstitial fibrosis, cardiac conduction abnormalities, pericarditis, cardiomyopathy, vasculitides, amyloidosis, congestive heart failure, respiratory failure. The cost of instrumental and laboratory tests was defined according to the tariffs applied by the Lombardy, Campania, and Lazio regions. Administration costs were included in the hospitalization costs for intravenous biologics. Subcutaneous agents were self-administered and, thus, no administration costs were considered for this route of administration. Mean annual total health care costs were estimated separately for different biologic treatments. The cost analysis was conducted from the perspective of the National Health Service. The currency reference used was the Euro $(€)$.

\section{Statistical analysis}

Continuous variables were reported as mean and standard deviation (median and range as appropriate), whereas categorical variables were expressed as numbers and percentages. When comparisons were made, groups were assessed and compared using the Student's $t$-test. Qualitative variables were expressed as absolute and relative frequencies. To control for confounding factors, we included in the model factors including age, sex, CCI, coexisting illnesses, and drug used; the analysis was conducted separately for naïve and established patients.

The $P$-values $<0.05$ were considered to be statistically significant, and all statistical analyses were conducted using SPSS statistical software for Windows, version 18.0 (SPSS Inc., Chicago, IL, USA).

\section{Results}

Of the total population of $2,100,000$ subjects $\geq 18$ years, patients available for analysis after applying the inclusion criteria were 594 (3 per 10,000 beneficiaries). Mean (SD) patient age at the index date was $53.5 \pm 13.5$ years. The majority of patients were female with a ratio of women to men of $3: 1$. 
Table I Demographic characteristics

\begin{tabular}{|c|c|c|c|c|c|c|}
\hline & $\begin{array}{l}\text { Abatacept } \\
(n=62 ; 10 \%)\end{array}$ & $\begin{array}{l}\text { Adalimumab } \\
(n=I 50 ; 25 \%)\end{array}$ & $\begin{array}{l}\text { Etanercept } \\
(n=229 ; 39 \%)\end{array}$ & $\begin{array}{l}\text { Golimumab } \\
(n=17 ; 3 \%)\end{array}$ & $\begin{array}{l}\text { Infliximab } \\
(n=82 ; \mid 4 \%)\end{array}$ & $\begin{array}{l}\text { Tocilizumab } \\
(n=54 ; 9 \%)\end{array}$ \\
\hline Age (years), mean $\pm S D$ & $53.1 \pm 12.7$ & $55.3 \pm 13.2$ & $52.6 \pm 13.8$ & $47.4 \pm 13.1$ & $54.4 \pm 12.7$ & $53.5 \pm 14.2$ \\
\hline Female, $\mathrm{n}(\%)$ & $44(71.0)$ & $119(79.3)$ & $174(76.0)$ & $12(70.6)$ & $58(70.7)$ & $36(66.7)$ \\
\hline $\begin{array}{l}\text { Charlson Comorbidity Index, } \\
\text { mean } \pm \text { SD }\end{array}$ & $2.7 \pm 1.9$ & $2.3 \pm 1.7$ & $2.3 \pm 1.5$ & $3.3 \pm 2.5$ & $2.7 \pm 1.4$ & $2.4 \pm 1.2$ \\
\hline \multicolumn{7}{|c|}{ Pre-index concomitant medication use } \\
\hline DMARD, n (\%) & $55(88.7)$ & $115(76.7)$ & I 78 (77.7) & $17(100.0)$ & $74(90.2)$ & $39(72.2)$ \\
\hline Antibiotics, $n(\%)$ & $42(67.7)$ & $82(54.7)$ & $130(56.8)$ & $12(70.6)$ & $49(59.8)$ & $30(55.6)$ \\
\hline Pain medications, n (\%) & $51(82.3)$ & $98(65.3)$ & $156(68.1)$ & $15(88.2)$ & $64(78.0)$ & $44(81.5)$ \\
\hline Biologic-naïve patients, $\mathrm{n}$ & 54 & 95 & 137 & 17 & 39 & 54 \\
\hline Patients without switches, $\mathrm{n}$ & 38 & 84 & 125 & 15 & 35 & 50 \\
\hline
\end{tabular}

Abbreviation: DMARD, disease-modifying antirheumatic drugs.

Patients' characteristics and prior health care resources utilization are summarized in Table 1 . The number and proportion of patients who received each index biologic were (in decreasing order): etanercept, 229 (39\%); adalimumab, 150 (25\%); infliximab, 82 (14\%); abatacept, 62 (10\%); tocilizumab, 54 (9\%); and golimumab, 17 (3\%) (Table 1). Golimumab was originally considered for the analysis, but due to the small sample size future analyses will be necessary to validate and confirm its data; therefore, golimumab was excluded from subsequent analyses. Patients who used other RA-related medication during the follow-up period are shown in Figure 1.

In case of the naïve patients without switches, the persistence rates for each biologic agent were: $78 \%$ for etanercept, $72 \%$ for tocilizumab, $71 \%$ for adalimumab, $69 \%$ for infliximab, and $64 \%$ for abatacept (Figure 2). Figure 3 shows the proportion of patients who underwent dose escalation during the period of study; dose escalation was $21.4 \%$ for infliximab, $11.5 \%$ for adalimumab, $5.6 \%$ for abatacept, $4 \%$ for tocilizumab, and $3.8 \%$ for etanercept. Among naïve patients without switches, the rates of hospitalization at 12 months of follow-up are summarized in Figure 4. Annual costs among all patients for each treatment was $€ 12,803$ for adalimumab, $€ 11,924$ for etanercept, $€ 11,830$ for tocilizumab, $€ 11,201$ for infliximab, and $€ 10,943$ for abatacept (Figure 5).

\section{Discussion}

This study provides an evaluation of drug utilization and costs in a cohort of RA patients treated with biologic agents. Differences in the route of administration and flexibility of dosing of these agents may result in different medication use profiles (eg, persistence, discontinuation, dose escalation, switching to a new biologic RA drug, and usage of RA-related co-medications) in real-life clinical setting. In the last few years, several network meta-analyses tried to compare biologic drugs used in RA. ${ }^{31}$ Consistent with previous studies ${ }^{29,22}$ and in line with the recommendations of Italian Society of Rheumatology pertaining to RA treatment, ${ }^{32}$ we found that etanercept, adalimumab, followed by infliximab were the most commonly used. There are variations in the usage of biologic agents among countries based on licensing, local guidelines, and policies. ${ }^{33}$

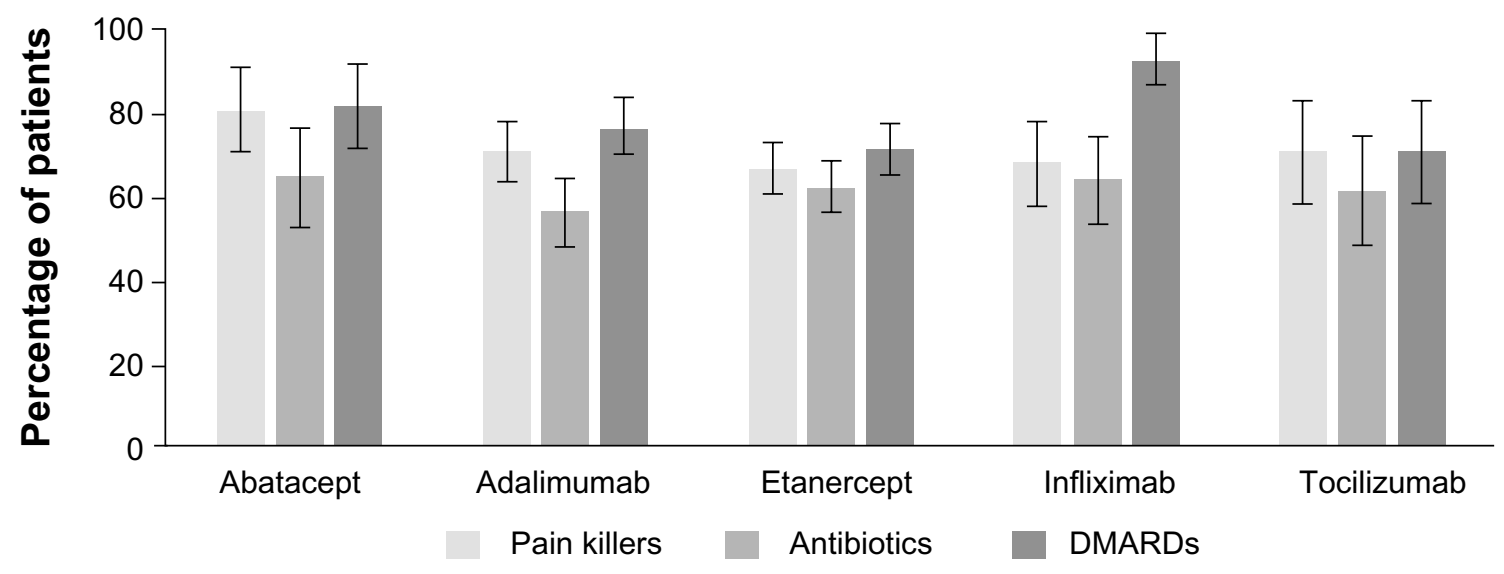

Figure I Concomitant medication use, follow-up period.

Abbreviation: DMARD, disease-modifying antirheumatic drugs. 


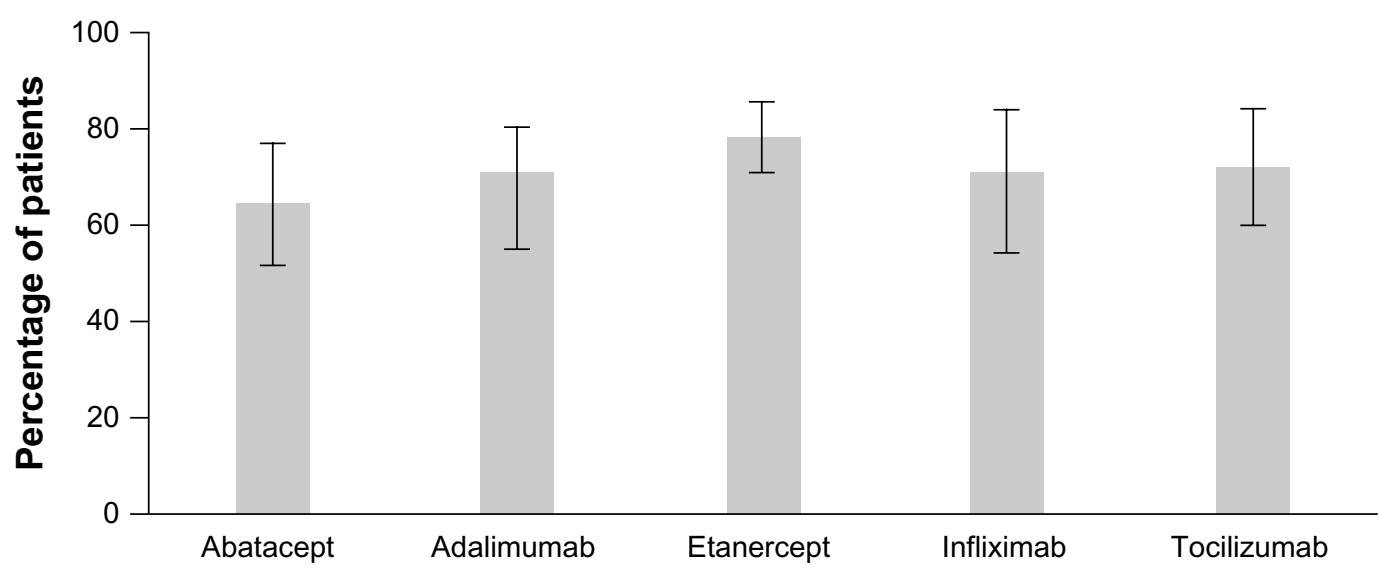

Figure 2 Persistence with treatment, naïve patients without switches.

The various structures of health care systems in different countries make comparisons between studies difficult. In addition, access to biologic drugs differs among countries. ${ }^{34}$

Glucocorticoids as well as nonsteroidal anti-inflammatory drugs and DMARDs are among the most important drugs used in the routine clinical practice and still play a decisive role in the management of diverse rheumatic conditions. ${ }^{35,36}$ Our patients showed similar treatment patterns as reported in a recent study. ${ }^{37}$ After 1 year of observation, a higher level of persistence was observed in the etanercept cohort with respect to those treated with other biologic agents. ${ }^{38,39}$ These results, however, must be kept with caution due to the differences of the sample size among the various analyzed biologics.

Taking therapies as prescribed is crucial for the achievement of the goals of RA treatment, which are to induce remission, to prevent joint damage and destruction, to prevent disability, and to improve quality of life. ${ }^{40}$ Studies of persistence with biologic therapy have yielded varying results. Higher persistence with infliximab has been reported in a US pharmacy database analysis, ${ }^{23}$ while some data from European registries showed the lowest persistent with infliximab. ${ }^{41,42}$ In contrast, data from a Danish registry showed that persistence was the highest with etanercept and the lowest with infliximab, with 56\% and $41 \%$ of patients, respectively, who persisted in the therapy at 2 years..$^{43}$

This analysis indicated that dose escalation was less frequent among patients treated with etanercept (3.8\%) and abatacept (5.6\%) compared with infliximab (21.4\%). The adalimumab dosage increase rate was $11.5 \%$; our results are in contrast with the Italian recommendations ${ }^{32}$ (at time of completion of the literature analysis), where the incremental dose of adalimumab does not seem to be helpful on clinical ground.

The results presented here are consistent with those reported from other published studies. ${ }^{17,37,40,42,44-51}$ It is important to note that the variation estimates in previous research may be due to the method of calculating dose escalation.

During the observation period, patients requiring incremental dose were the same patients with the highest rate of

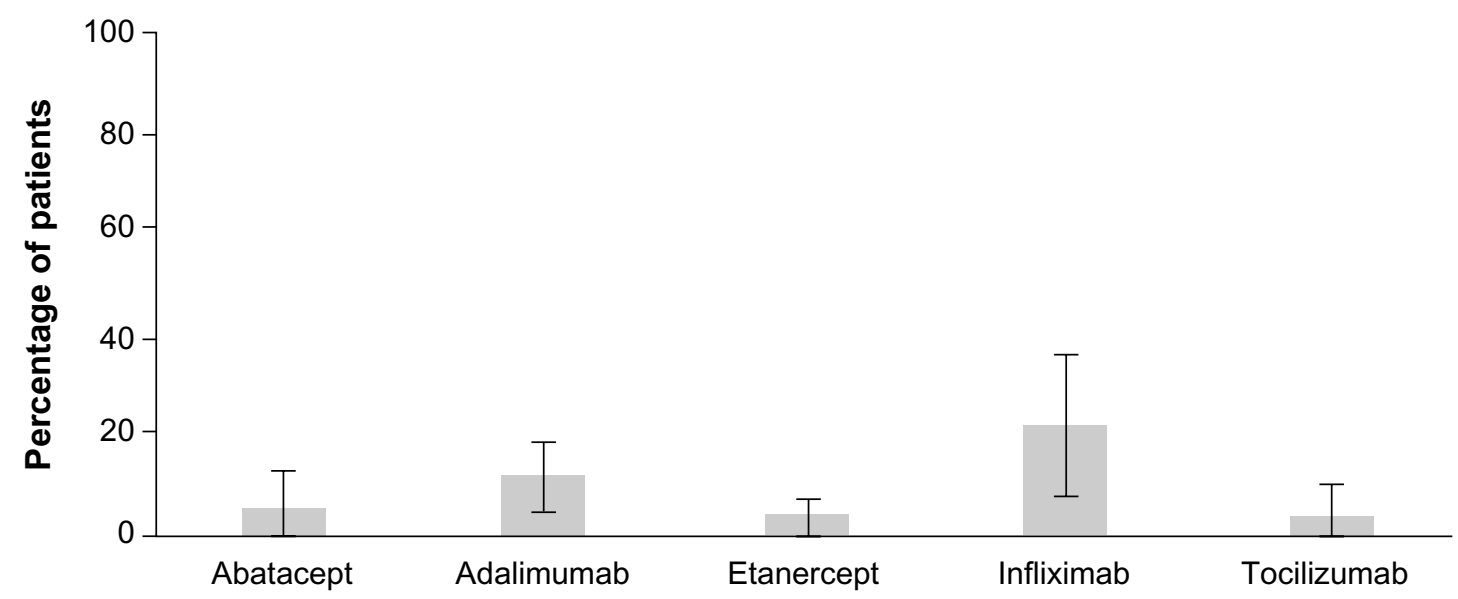

Figure 3 Dose escalation, naïve patients without switches. 


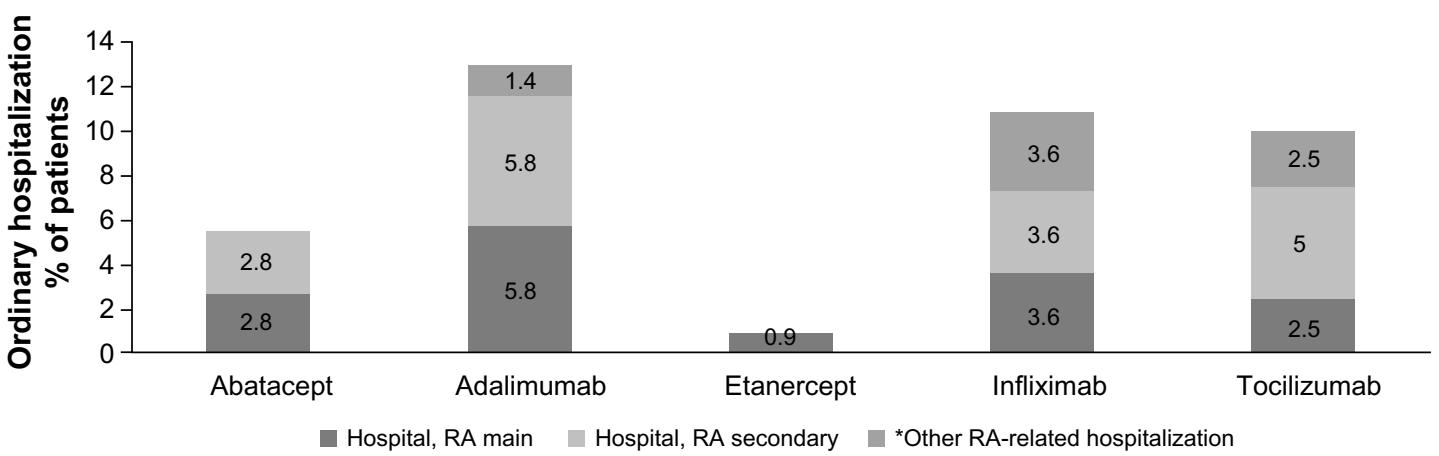

Figure 4 Hospitalizations, naïve patients without switches.

Note: *Other inherent hospitalizations considered for disease staging (uveitis, fusion of metacarpophalangeal interphalangeal joint spaces, carpal tunnel syndrome, anemia, Felty's syndrome, pneumoconiosis, interstitial fibrosis, cardiac conduction abnormalities, pericarditis, cardiomyopathy, vasculitides, amyloidosis, congestive heart failure, and respiratory failure).

Abbreviation: RA, rheumatoid arthritis.

hospitalizations. It may be explained by previous investigations ${ }^{52}$ that show the association between dose escalation and high risk of adverse event despite only a few studies to have evaluated the effect of dose escalation on clinical outcomes. ${ }^{53,54}$

Our analysis also evaluated the cost of management of RA patients treated with biologic agents in a real-world setting. Several studies in the clinical practice setting have found relationship between dose escalation and significant cost increase. ${ }^{17,22,45,52}$ Previous studies have suggested that patients with higher persistence rates have lower medical (non-pharmacy) costs, suggesting that they used fewer medical resources, which may indicate a positive effect on quality life..$^{23}$ Although our results showed that persistence and escalating the dose of treatment have influenced the overall health care cost, it remains difficult to compare these data with other studies because few analyses included all biologic agents approved for RA treatment and further research is needed using a larger sample to validate these results. Additionally, our findings showed that a consistent percentage of patients underwent dose escalation; because of this, we used the persistence rates to explore the discontinuation of medication rather than the adherence rates, a method influenced by dose-escalating treatments.

In this analysis, the cohort of patients reflected clinicalpractice situations, but the results must be interpreted in the context of several limitations. Comparisons between biologics were complicated by large differences in sample size between the most commonly used and the other biologics. Based on the study time period, there were an insufficient number of patients on biologic therapies (eg, anakinra,

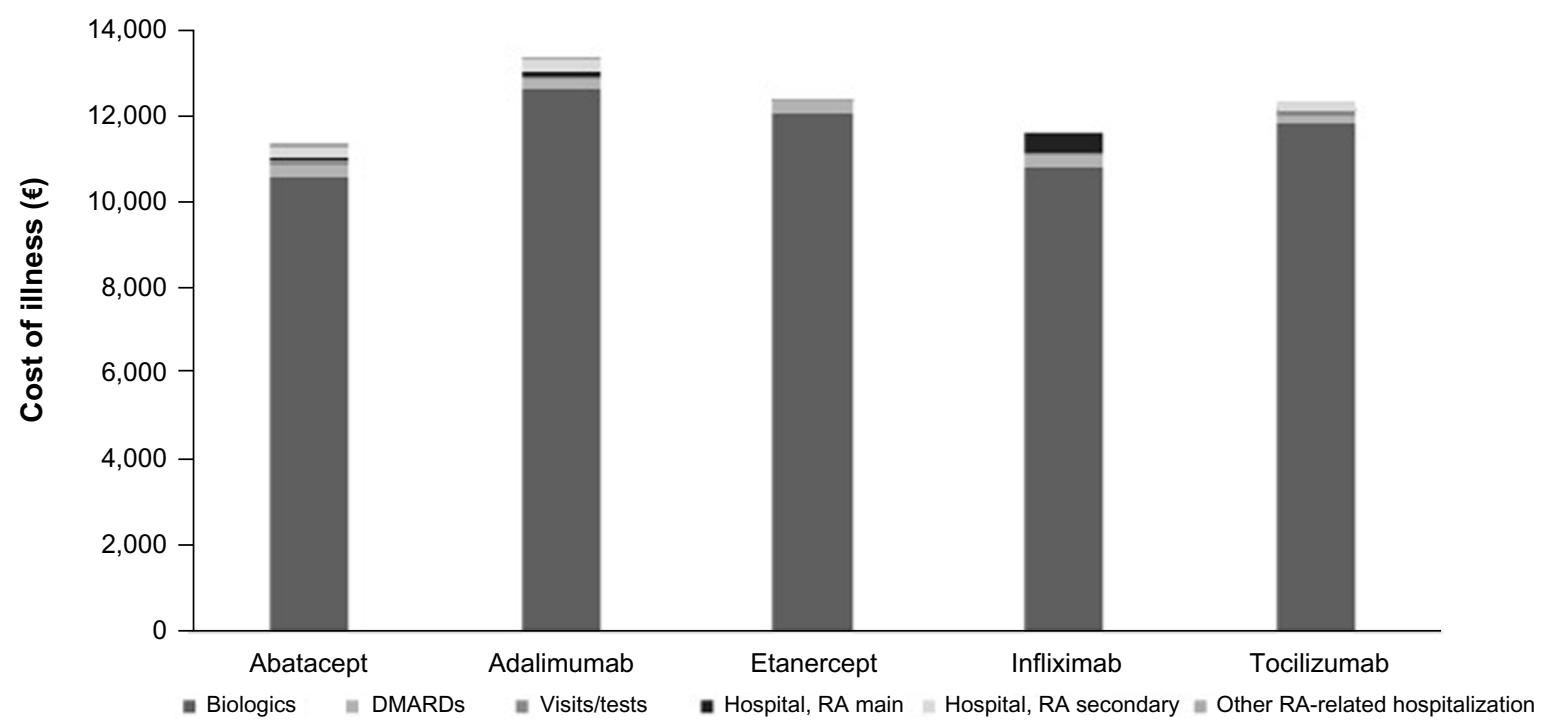

Figure 5 Cost of illness, naïve patients without switches.

Abbreviations: DMARD, disease-modifying antirheumatic drugs; RA, rheumatoid arthritis. 
certolizumab pegol, golimumab, rituximab) for 12 or more months to include in the analysis.

Because this was a retrospective analysis of administrative databases, important clinical information such as severity of disease, clinical response to treatment, clinical decision drivers to administer a given biologic agent (ie, high-risk patient), and the reason of switch or dose escalation is not captured. The major limitation is the lack of clinical severity at baseline, leading us to conclude that channeling bias could have a major contribution to all of the findings. The absence of weight information increases the difficulty in capturing dose for infusion-administered drugs such as infliximab. The choice of different biologic agents is usually based on their safety profile, route of administration, costs, and patient profiles.

\section{Conclusion}

Despite our limitations and that the head-to-head comparisons were difficult because the clinical status of subjects enrolled were not available from the administrative database, our analysis provides an illustration of biologic therapy utilization in adult patients with RA, these observations could be used by decision makers to support therapeutic decisions.

\section{Acknowledgments}

We would like to thank Dr Rossana Piccinelli and Dr Francesca Atzeni (LHU di Bergamo), Dr Alessandra Blasi and Dr Eugenia Pagnozzi (Area Politiche del Farmaco LHU Roma D), LHU Caserta. The abstract of this paper was presented at the International Society for Pharmacoeconomics and Outcomes Research (ISPOR) 17th Annual European Congress, Amsterdam (the Netherlands) 2014, named "Drug usage analysis and health care resources consumption in patients with rheumatoid arthritis as a poster presentation with interim findings". The poster's abstract was published in "Poster Abstracts" in 17:7, PMS 6 journal Value in Health. ${ }^{55}$ Manuscript development was supported by unconditional funding from Bristol-Myers Squibb.

\section{Author contributions}

All authors contributed toward data analysis, drafting, and revising the paper and agree to be accountable for all aspects of the work.

\section{Disclosure}

$\mathrm{CN}$ is employee of Bristol-Myers Squibb. The authors report no other conflicts of interest in this work.

\section{References}

1. Pincus T, Callahan LF. What is the natural history of rheumatoid arthritis? Rheum Clin North Am. 1993;19:123-151.

2. Gibofsky A. Epidemiology, pathophysiology, and diagnosis of rheumatoid arthritis: a synopsis. Am J Manag Care. 2014;20:s128-s145.

3. Smolen JS, Landewé R, Breedveld FC, et al. EULAR recommendations for the management of rheumatoid arthritis with synthetic and biological disease-modifying antirheumatic drugs: 2013 update. Ann Rheum Dis. 2014;73:492-509.

4. Tanaka, Y. Next stage of RA treatment: is TNF inhibitor-free remission a possible treatment goal? Ann Rheum Dis. 2013;(72 Suppl 2): ii124-ii127.

5. Shi G, Liu Y. Editorial: biologics in autoimmune diseases. Curr Pharm Biotechnol. 2014;15:509.

6. Enbrel (etanercept) [prescribing information]. London, UK: European Medicines Agency; last update May 30, 2014. Available from: http://www.ema.europa.eu/ema/index.jsp?curl=pages/ medicines/human/medicines/000262/human_med_000764. jsp\&mid=WC0b01ac058001d124

7. Humira (Adalimumab) [prescribing information]. London, UK European Medicines Agency; last update October 21, 2014. Available from: http://www.ema.europa.eu/ema/index.jsp?curl=pages/ medicines/human/medicines/000481/human_med_000822. jsp\&mid=WC0b01ac058001d124. Accessed May 30, 2014.

8. Remicade (infliximab) [prescribing information]. London, UK: European Medicines Agency; last update May 30, 2012. Available from: http://www.ema.europa.eu/ema/index.jsp?curl=pages/ medicines/human/medicines/000240/human_med_001023. jsp\&mid=WC0b01ac058001d124.

9. Orencia (Abatacept) [prescribing information]. London, UK: European Medicines Agency; last update October 21, 2014. Available from: http://www.ema.europa.eu/docs/en_GB/document_library/ EPAR_-_Product_Information/human/000701/WC500048935.pdf.

10. RoActemra (Tocilizumab) [prescribing information]. London, UK: European Medicines Agency; last update October 21, 2014. Available from: http://www.ema.europa.eu/docs/en_GB/document_library/ EPAR_-_Product_Information/human/000955/WC500054890.pdf.

11. Cimzia (Certolizumab pegol) [prescribing information]. London, UK: European Medicines Agency; last update October 21, 2014. Available from: http://www.ema.europa.eu/docs/en_GB/document_library/ EPAR_-_Product_Information/human/001037/WC500069763.pdf.

12. Kineret (Anakinra) [prescribing information]. London, UK: European Medicines Agency; last update October 21, 2014. Available from: http://www.ema.europa.eu/docs/en_GB/document_library/EPAR_Product_Information/human/000363/WC500042310.pdf.

13. Simponi (Golimumab) [prescribing information]. London, UK: European Medicines Agency; last update October 21, 2014. Available from: http://www.ema.europa.eu/docs/en_GB/document_library/ EPAR_-_Product_Information/human/000992/WC500052368.pdf

14. Mabthera (Rituximab) [prescribing information]. London, UK: European Medicines Agency; last update October 21, 2014. Available from: http://www.ema.europa.eu/docs/en_GB/document_library/ EPAR_-_Product_Information/human/000165/WC500025821.pdf.

15. Singh JA, Christensen R, Wells GA, et al. A network meta-analysis of randomized controlled trials of biologics for rheumatoid arthritis: a Cochrane overview. CMAJ. 2009;181:787-796.

16. Gaujoux-Viala C, Gossec L, Cantagrel A, et al. Recommendations of the French Society for Rheumatology for managing rheumatoid arthritis. Joint Bone Spine. 2014;81:287-297.

17. Cannon GW, DuVall SL, Haroldsen CL, et al. Persistence and dose escalation of tumor necrosis factor inhibitors in US veterans with rheumatoid arthritis. J Rheumatol. 2014;41:1935-1943.

18. Bendtzen K. Personalized medicine: theranostics (therapeutics diagnostics) essential for rational use of tumor necrosis factor-alpha antagonists. Discov Med. 2013;15:201-211.

19. Punzi L, Matucci Cerinic M, Cantini F, et al. Treatment patterns of antiTNF agents in Italy: an observational study. Reumatismo. 2011;63: 18-28. 
20. Moots RJ, Haraoui B, Matucci-Cerinic M, et al. Differences in biologic dose-escalation, non-biologic and steroid intensification among three anti-TNF agents: evidence from clinical practice. Clin Exp Rheumatol. 2011;29:26-34.

21. Schabert VF, Watson C, Joseph GJ, Iversen P, Burudpakdee C, Harrison DJ. Costs of tumor necrosis factor blockers per treated patient using real-world drug data in a managed care population. JManag Care Pharm. 2013;19:621-630.

22. Schabert VF, Watson C, Gandra SR, Goodman S, Fox KM, Harrison DJ. Annual costs of tumor necrosis factor inhibitors using real-world data in a commercially insured population in the United States. J Med Econ. 2012;15:264-275.

23. Tang B, Rahman M, Waters HC, Callegari P. Treatment persistence with adalimumab, etanercept, or infliximab in combination with methotrexate and the effects on health care costs in patients with rheumatoid arthritis. Clin Ther. 2008;30:1375-1384.

24. Wu E, Chen L, Birnbaum H, Yang E, Cifaldi M. Cost of care for patients with rheumatoid arthritis receiving TNF-antagonist therapy using claims data. Curr Med Res Opin. 2007;23:1749-1759.

25. Fautrel B, Verstappen SM, Boonen A. Economic consequences and potential benefits. Best Pract Res Clin Rheumatol. 2011;25:607-624.

26. Di Bari M, Balzi D, Roberts AT, et al. Prognostic stratification of older persons based on simple administrative data: development and validation of the 'Silver Code,' to be used in emergency department triage. J Gerontol Biol Sci Med Sci. 2010;65:159-164.

27. Ministry of Labour, Health and Social Policies. Annual report on the hospitalization activity. 2005. Available from: http://www.ministerosalute. it/programmazione/sdo/sezDocumenti.jsp?id=148\&label=osp.

28. Gonnella JS, Louis DZ, Gozum MVE, Callahan CA, Barnes CA. Disease Staging Clinical and Coded Criteria. Version 5.26. Ann Arbor, MI: Thomson Medstat; 2010. Accessed June 28, 2014.

29. Bonafede MM, Gandra SR, Watson C, Princic N, Fox KM. Cost per treated patient for etanercept, adalimumab, and infliximab across adult indications: a claims analysis. Adv Ther. 2012;29:234-248.

30. Darkow T, Chastek B, Rosenblatt L, et al. Dose escalation among rheumatoid arthritis patients treated with infliximab or abatacept: comparison in claims data. [abstract]. Arthritis Rheum. 2011;63(Suppl 10):1221.

31. Migliore A, Ballanti E, Lagana B, Martin LS, Frediani B. Biologic agents for rheumatoid arthritis: can we hypothesize new strategies of treatment? Med Hypotheses. 2014;82:117-121.

32. Caporali R, Conti F, Alivernini S, et al. Recommendations for the use of biologic therapy in rheumatoid arthritis: update from the Italian Society for Rheumatology I. Efficacy. Clin Exp Rheumatol. 2011;29:S7-S14.

33. Tayar JH, Suarez-Almazor ME. New understanding and approaches to treatment in rheumatoid arthritis. Br Med Bull. 2010;94:201-214.

34. Jonsson B, Kobelt G, Smolen J. The burden of rheumatoid arthritis and access to treatment: uptake of new therapies. Eur J Health Econ. 2008;8(Supp1 2):S61-S86.

35. Al-Bishri J, Attar S, Bassuni N, et al. Comorbidity profile among patients with rheumatoid arthritis and the impact on prescriptions trend. Clin Med Insights Arthritis Musculoskelet Disord. 2013;6:11-18.

36. Gaffo A, Saag KG, Curtis JR. Treatment of rheumatoid arthritis. Am J Health Syst Pharm. 2006;63:2451-2465.

37. Ogale S, Hitraya E, Henk HJ. Patterns of biologic agent utilization among patients with rheumatoid arthritis: a retrospective cohort study. BMC Musculoskelet Disord. 2011;12:204.

38. FidderHH, SingendonkMM, van der Have M, Oldenburg B, van Oijen MG. Low rates of adherence for tumor necrosis factor-alpha inhibitors in Crohn's disease and rheumatoid arthritis: results of a systematic review. World J Gastroenterol. 2013;19:4344-4350.

39. Degli Esposti L, Sangiorgi D, Perrone V, et al. Adherence and resource use among patients treated with biologic drugs: findings from BEETLE study. Clinicoecon Outcomes Res. 2014;6:401-407.
40. Fisher MD, Watson C, Fox KM, Chen YW, Gandra SR. Dosing patterns of three tumor necrosis factor blockers among patients with rheumatoid arthritis in a large United States managed care population. Curr Med Res Opin. 2013;29:561-568.

41. Marchesoni A, Zaccara E, Gorla R, et al. TNF-alpha antagonist survival rate in a cohort of rheumatoid arthritis patients observed under conditions of standard clinical practice. Ann N Y Acad Sci. 2009;1173: $837-846$.

42. Ramirez-Herraiz E, Escudero-Vilaplana V, Alañón-Plaza E, et al. Efficiency of adalimumab, etanercept and infliximab in rheumatoid arthritis patients: dosing patterns and effectiveness in daily clinical practice. Clin Exp Rheumatol 2013;31:559-565.

43. Hetland ML, Christensen IJ, Tarp U, et al. Direct comparison of treatment responses, remission rates, and drug adherence in patients with rheumatoid arthritis treated with adalimumab, etanercept, or infliximab: results from eight years of surveillance of clinical practice in the nationwide Danish DANBIO registry. Arthritis Rheum. 2010;62:22-32.

44. Schabert VF, Bruce B, Ferrufino CF, et al. Disability outcomes and dose escalation with etanercept, adalimumab, and infliximab in rheumatoid arthritis patients: a US-based retrospective comparative effectiveness study. Curr Med Res Opin. 2012;28:569-580.

45. Bonafede MM, Gandra SR, Fox KM, Wilson KL. Tumor necrosis factor blocker dose escalation among biologic naive rheumatoid arthritis patients in commercial managed-care plans in the 2 years following therapy initiation. J Med Econ. 2012;15:635-643.

46. Harrison DJ, Huang X, Globe D. Dosing patterns and costs of tumor necrosis factor inhibitor use for rheumatoid arthritis. Am J Health Syst Pharm. 2010;67:1281-1287.

47. Huang X, Gu NY, Fox KM, Harrison DJ, Globe D. Comparison of methods for measuring dose escalation of the subcutaneous TNF antagonists for rheumatoid arthritis patients treated in routine clinical practice. Curr Med Res Opin. 2010;26:1637-1645.

48. Ollendorf DA, Klingman D, Hazard E, Ray S. Differences in annual medication costs and rates of dosage increase between tumor necrosis factor-antagonist therapies for rheumatoid arthritis in a managed care population. Clin Ther. 2009;31:825-835.

49. Blume SW, Fox KM, Joseph G, Chuang CC, Thomas J, Gandra SR. Tumor necrosis factor-blocker dose escalation in rheumatoid arthritis patients in a pharmacy benefit management setting. Adv Ther. 2013;30:517-527.

50. Greenberg JD, Reed G, Decktor D, et al. A comparative effectiveness study of adalimumab, etanercept and infliximab in biologically naive and switched rheumatoid arthritis patients: results from the US CORRONA registry. Ann Rheum Dis. 2012;71:1134-1142.

51. Gilbert TD Jr, Smith D, Ollendorf DA. Patterns of use, dosing, and economic impact of biologic agent use in patients with rheumatoid arthritis: a retrospective cohort study. BMC Musculoskelet Disord. 2004;5(1):36.

52. Joyce AT, Gandra SR, Fox KM, Smith TW, Pill MW. National and regional dose escalation and cost of tumor necrosis factor blocker therapy in biologic-naive rheumatoid arthritis patients in US health plans. J Med Econ. 2014;17:1-10.

53. Curtis JR, Chen L, Luijtens K, et al. Dose escalation of certolizumab pegol from $200 \mathrm{mg}$ to $400 \mathrm{mg}$ every other week provides no additional efficacy in rheumatoid arthritis: an analysis of individual patient-level data. Arthritis Rheum. 2011;63:2203-2208.

54. Weinblatt ME, Schiff MH, Ruderman EM, et al. Efficacy and safety of etanercept $50 \mathrm{mg}$ twice a week in patients with rheumatoid arthritis who had a suboptimal response to etanercept $50 \mathrm{mg}$ once a week: results of a multicenter, randomized, double-blind, active drug-controlled study. Arthritis Rheum. 2008;58:1921-1930.

55. Drug usage analysis and health care resources consumption in patients with rheumatoid arthritis. International Society for Pharmacoeconomics and Outcomes Research (ISPOR) 17th Annual European Congress, Amsterdam (NL) 2014. Value in Health 17:7, PMS6. 


\section{Publish your work in this journal}

Biologics: Targets \& Therapy is an international, peer-reviewed journal focusing on the patho-physiological rationale for and clinical application of Biologic agents in the management of autoimmune diseases, cancers or other pathologies where a molecular target can be identified. This journal is indexed on PubMed Central, CAS, EMBase, Scopus
Dovepress

and the Elsevier Bibliographic databases. The manuscript management system is completely online and includes a very quick and fair peerreview system, which is all easy to use. Visit http://www.dovepress. com/testimonials.php to read real quotes from published authors. 